\title{
Transfer of technology regarding correction of congenital talipesequinovarus by ponseti method of treatment to doctors working at peripheral hospitals of eastern region of Nepal covered by BPKIHS, Dharan.
}

\author{
R Rijal ${ }^{1}$, BP Shrestha ${ }^{1}$, GP Khanal ${ }^{1}$, P Chaudhary ${ }^{1}$, R Maharjan $^{1}$, SR Paneru ${ }^{1}$, P Rai $^{2}$ \\ Department of Orthopedics, School of Public Health and Community Medicine \\ B.P. Koirala Institute of Health Sciences, Dharan, Nepal
}

\begin{abstract}
Background: Ponseti method of manipulation and casting has been standard non operative method of treatment for idiopathic clubfoot. We have conducted this study to find out whether Ponseti method of correction can be taught to doctors working at district hospital. Objective: To assess the knowledge, familiarize the Ponseti method of correction and to decrease the need of surgery regarding the congenital talipesequinovarus. Method: We conducted prospective study among doctors working in the district hospitals of eastern Nepal. We assessed knowledge and practice regarding clubfoot management before and after the intervention by questionnaire based method. The data were analyzed using before and after difference for magnitude and paired $t$ test for significance. Result: 13 doctors were included in the study. Among 13 participants,one $(7.69 \%)$ had formal orthopedic training. Only $30 \%$ of the participants had more than $60 \%$ correct response regarding questionnaires regarding knowledge of clubfoot. $40 \%$ of participants had done referral of cases to orthopedic centre. One (7.69\%) of the participants had applied Ponseti cast. 61\% percent of the participants responded more than $60 \%$ correctly at the final follow up at one year. Conclusion: The study shows that the knowledge and practice regarding Clubfoot correction is inadequate and hence teaching of Ponseti method was useful in the district hospital.
\end{abstract}

Key words: Clubfoot ponseti method

\footnotetext{
Address of correspondence

Dr. Raju Rijal

Additional Professor

Department of Orthopedics

B.P. Koirala Institute of Health Sciences, Dharan

Phone No: 00977-25-525555-2016

Email: rijalraju@yahoo.com
} 


\section{Introduction}

Nepal is a developing country with a current population around 30 million people and very few orthopedic surgeons or physiotherapists. ${ }^{1}$ Although no correct estimation of congenital talipesequinovarus deformity has been known to Nepalese population, rough estimate of 6-7/1000 live birth has been estimated which is far more than worldwide incidence. If these feet are not corrected early then severe deformities can develop, requiring complex surgery. ${ }^{2-4}$

Some tertiary centers are managing the cases, however, these efforts are not adequate. Most of the patients live far from these centers and most of the people had no idea regarding clubfoot treatment. They don't treat their babies, they present late at the hospital once the deformities become permanent or established or they come to get disability certificate..$^{2-3}$

Ponseti method has proven to be successful around the globe, in both industrialized countries and developing nations. ${ }^{4-20}$ In many settings, non physician practitioners are primarily responsible for the casting phase of treatment, particularly in areas with a shortage of physicians. ${ }^{4}$ Internationally, researchers are effectively expanding the scope of clubfoot treatment: older children, postsurgical recurrent deformities, and non idiopathic clubfoot. The barriers that undermine the outcomes of a Ponseti clubfoot program are primarily poverty and non compliance with the extended post casting brace protocol. ${ }^{21}$

Hence we have conducted this study to assess the knowledge and practices regarding treatment of clubfoot, to familiarize the Ponseti method of correction and to decrease the need of surgery among doctors working in the district hospitals of eastern Nepal.

\section{Methods}

We conducted interventional study among doctors working at district hospitals of eastern region of Nepal from January 2010 to January 2011 for one year. Those doctors, who were practicing the clubfoot treatment and provided informed consent, were included in the study. Those doctors who were not practicing and not willing to participate in the study were excluded from the study. Protocol was approved from research committee of B.P. Koirala Institute of Health Sciences and ethical clearance was taken from institutional ethical review board of BP Koirala Institute of Health Sciences. Standard pilot tested proforma containing questionnaires regarding basic knowledge of clubfoot and the standard treatment practice principles was used for evaluation of knowledge and practice. The questionnaires were distributed to the doctors at the beginning of study and response was 
obtained. Demonstration class was taken using standard Ponseti method of clubfoot correction by the researcher ${ }^{22}$. They were given contact details of the demonstrator and in any case that they wanted to contact regarding treatment or complication, they could have access to experts at any point of time. They were also advised about the referral centre.

When they called for any assistance regarding treatment and referral of the patient, the researcher visited the periphery hospital and carried necessary action. Then after one year of follow up, questionnaires were distributed again to assess the knowledge and practices of treatment of clubfoot and responses were obtained. The data were entered in microsoft excel 8 sheet and analyzed using SPSS software. Paired $t$ test was used to find out the pre and post intervention differences, in the knowledge and practices of the clubfoot treatment.

\section{Results}

Among 15 doctors, two were excluded from the study due to unwillingness to participate in the research, from five hospitals of eastern region of Nepal. All the doctors were male and only one had formal orthopedic training. All the response regarding knowledge of clubfoot has been shown in table 1 .

Table 1: Showing frequencies of response regarding knowledge of congenital talipesequinovarus

\begin{tabular}{|l|c|c|}
\hline \multicolumn{1}{|c|}{ Questions } & \multicolumn{2}{c|}{$\begin{array}{c}\text { Correct responses (Total } \\
\text { sample size size=13) }\end{array}$} \\
\cline { 2 - 3 } & \multicolumn{2}{|c|}{ Pre } \\
\hline What are the sites of deformities in CTEV? & 7 & 12 \\
\hline Description of ankle and foot joint & 8 & 11 \\
\hline Description of ankle and foot deformities & 7 & 10 \\
\hline Which of the following joint is included in CTEV deformity? & 6 & 10 \\
\hline Which are the Deformities inclubfoot? & 7 & 11 \\
\hline Which is the site of Equinus in the clubfoot? & 8 & 11 \\
\hline Which is the site of inversion in the clubfoot? & 5 & 11 \\
\hline Where does adduction occur in the clubfoot? & 6 & \\
\hline $\begin{array}{l}\text { Which of the following is the appropriate sequence of } \\
\text { correction of clubfoot? }\end{array}$ & & \\
\hline
\end{tabular}




\begin{tabular}{|l|c|c|}
\hline $\begin{array}{l}\text { In which position should the thumb be placed during } \\
\text { correction of varus deformity? }\end{array}$ & 1 & 11 \\
\hline $\begin{array}{l}\text { Which of the following is the Ponseti method of correction for } \\
\text { treatment of clubfoot? }\end{array}$ & 1 & 12 \\
\hline What is the duration of cast inPonseti method treatment? & 0 & 11 \\
\hline $\begin{array}{l}\text { What is the duration of cast in traditional method of } \\
\text { treatment? }\end{array}$ & 5 & 10 \\
\hline Is the bracing following casting necessary? & 7 & 10 \\
\hline In your opinion, do all the CTEV cases need surgery? & 1 & 12 \\
\hline
\end{tabular}

Table 2: Showing knowledge score Table 2 shows that only two (15.3\%) regarding congenital talipesequinovarus participants responded $60 \%$ of the

\begin{tabular}{|l|l|l|}
\hline $\begin{array}{l}\text { Knowledge } \\
\text { score }\end{array}$ & $\begin{array}{l}\text { Pre } \\
\text { intervention }\end{array}$ & $\begin{array}{l}\text { Post } \\
\text { intervention }\end{array}$ \\
\hline$<5$ & 3 & 0 \\
\hline $5-9$ & 8 & 1 \\
\hline$>10$ & 2 & 12 \\
\hline
\end{tabular}
questionnaires correctly before the intervention. In case of post intervention study, $92.3 \%$ participants responded more than $60 \%$ of the questionnaires correctly.

All the response regarding practices of clubfoot treatment before and after the intervention has been shown in table 3 .

Table 3: Practices of treatment of congenital talipesequinovarus.

\begin{tabular}{|l|l|l|l|}
\hline \multirow{2}{*}{ Questions } & \multirow{2}{*}{ Responses } & \multicolumn{2}{|c|}{ Frequencies (13) } \\
\cline { 3 - 4 } & & Pre test & Post test \\
\hline Have you managed cases of clubfoot? & Yes & 2 & 13 \\
\cline { 2 - 4 } & No & 11 & 0 \\
\hline \multirow{2}{*}{ How many cases have you treated until now? } & $>10$ cases & 2 & 9 \\
\cline { 2 - 4 } & $<10$ cases & 11 & 4 \\
\hline \multirow{2}{*}{ Which treatment method did you use? } & Conservative & 10 & 13 \\
\cline { 2 - 4 } & Operative & 3 & 0 \\
\hline Did you use Ponseti method of treatment? & Yes & 4 & 13 \\
\cline { 2 - 4 } & No & 9 & 0 \\
\hline Did you manage patient at youngest age? & Yes & 1 & 8 \\
\hline
\end{tabular}




\begin{tabular}{|l|l|l|l|}
\hline & No & 12 & 5 \\
\hline Did you manage patient at older age only? & Yes & 12 & 8 \\
\cline { 2 - 4 } & No & 1 & 5 \\
\hline Duration of each cast for one week only? & Yes & 0 & 8 \\
\cline { 2 - 4 } & No & 13 & 5 \\
\hline Duration of entire treatment with casting less & Yes & 2 & 11 \\
\cline { 2 - 4 } than 3 months? & No & 11 & 2 \\
\hline Correction was confirmed by clinical & Clinical & 7 & 12 \\
\cline { 2 - 4 } examination/radiological & Radiological & 6 & 1 \\
\hline Denis Browne splint was applied? & Yes & 3 & 13 \\
\cline { 2 - 4 } & No & 10 & 0 \\
\hline \multirow{2}{*}{$\begin{array}{l}\text { Did you refer for surgery after conservative } \\
\text { method? }\end{array}$} & Yes & 8 & 11 \\
\cline { 2 - 4 } & No & 5 & 2 \\
\hline Did you refer for surgery after Ponseti method & Yes & 7 & 13 \\
\cline { 2 - 4 } of casting? & No & 6 & 0 \\
\hline Do you want to use Ponseti method as your & Yes & 6 & 13 \\
\cline { 2 - 4 } preferred method of treatment? & No & 7 & 0 \\
\hline Have you referred patients without treatment? & Yes & 3 & 6 \\
\cline { 2 - 4 } & No & 10 & 7 \\
\hline
\end{tabular}

Table 4: Showing value of paired $t$ test

\begin{tabular}{|l|l|l|l|l|}
\hline \multirow{2}{*}{ Variables } & \multicolumn{2}{|c|}{ Mean \pm SD } & \multirow{2}{*}{ P value } & \multirow{2}{*}{ Remarks } \\
\cline { 2 - 3 } & \multicolumn{1}{|c|}{ Pre } & \multicolumn{1}{|c|}{ Post } & \\
\hline Knowledge & $6.46 \pm 2.53$ & $11.92 \pm 1.93$ & $<0.001$ & Significant \\
\hline Practice & $5.15 \pm 2.37$ & $8.77 \pm 2.27$ & $<0.001$ & Significant \\
\hline
\end{tabular}

Table 4 shows that knowledge and practices regarding clubfoot treatment had been changed by formal training session by Ponseti method in the district hospital in which $p$ value is $<0.001$ that is highly significant.

\section{Discussion}

Clubfoot is congenital structural impairment that, if untreated or inadequately treated 
leads to deformity. Overall the establishment of a nationwide clubfoot treatment programme will be of benefit to a large number of children with clubfeet and the families. In a poor country with much demand on health funding, many challenges remain. The cost of plaster of Paris and splints, hospital charge, time spent by the parents to attend the hospital, and patient compliance are vital factors for adequate treatment. ${ }^{21}$

Ponseti method should be considered the best treatment modality for all children with clubfeet. In the developing world, where most neglected clubfeet occur emphasis should continue to the training of practitioners and implementation of program to reach all affected children. ${ }^{22}$

Effective management is dependent on the compliance of parents to the treatment for clubfoot. A cross sectional descriptive survey using a questionnaire identified the barriers encountered in bringing their children for treatment during the plaster casting stage of managing clubfoot at Mulago Hospital in Uganda. $90 \%$ of parents had attended weekly clinics with $67 \%$ indicating that they did not know about clubfoot and its treatment. The study found a significant association between compliance and transport costs ( $p-0.014)$; distance travelled $(p=0.005)$ and family support $(p=0.028)$. This study shows that if effective clubfoot programme is available near to their home, parent will attend the hospital regularly and treat their children. Other barriers highlighted include the need to improve the communication skills between clinicians offering treatment to children with clubfoot and their parents. Informed parents could assist with compliance to treatment. ${ }^{23}$ In some studies plaster applied by physiotherapist was associated with fewer recurrences and a less frequent need for additional procedures. The introduction of the physiotherapist supervised clubfoot clinic at their institution has been effective without compromising the quality of care of children with clubfoot deformity. ${ }^{24,25}$

In this study $92.3 \%$ doctors had no formal orthopedic training and these are the persons who basically care; provide advice regarding treatment and referral of the patients. In this study regarding knowledge of clubfoot only two $(15.3 \%)$ participants responded $60 \%$ of the questionnaires correctly before the intervention. In case of post intervention study $92.3 \%$ participant responded more than $60 \%$ of questionnaires correctly, which shows that our intervention programme was useful. In this study, no participants had correct practice regarding clubfoot management before the intervention whereas after intervention all participants had started standard practices regarding treatment of clubfoot. Those standard practices were in the form of application of cast, timely advice 
and referral to centers where adequate management can be done.

\section{Conclusion}

This study showed that knowledge and practices regarding clubfoot treatment had been changed by formal training session on Ponseti method in the district hospitals. This study shows that intervention programme was very useful. If we can further encourage the health workers regarding casting part of clubfoot management we can even train other health workers like auxiliary health worker and health assistants apart from doctors because they are the primary contact persons to the patient's surroundings like sub health post, health post and primary health care centers.

\section{References}

1. Population division of department of economic and social affairs of the United Nations Secretariat (2009). World Population Prospects; 2008 Revision. Highlights. New York: United Nations. Table $A_{2}$.

2. Rijal R, Shrestha BP, Singh GK, Singh MP, Khanal GP, Rai P. Authors' reply. Indian J Orthop 2011; 45: 189.

3. Rijal R, Shrestha BP, Singh GK, Singh MP, Khanal GP, Rai P. Comparison of Ponseti and kite 's method of treatment for idiopathic clubfoot. Indian J Orthop 2010; 44: 202-7.

4. Spiegel DA, Shrestha OP, Sitoula P et al. Ponseti method for untreated idiopathic clubfeet in Nepalese patients from 1 to 6 years of age. ClinOrthopRel Res 2009; 467(5): 1164-70.

5. Herzenberg JE, Radler C, Bor N. Ponseti versus traditional methods of casting for idiopathic clubfoot. J PediatrOrthop. 2002; 22: 517-21.

6. Ponseti IV. Treatment of congenital clubfoot. Current concepts review. J Bone Joint Surg (Am). 1992; 74(3): 44854.

7. Wimbley RL. Idiopathic clubfoot. CurrOpinOrthop 2005; 16: 451-56.

8. Laaveg SJ, Ponseti IV. Long-term results of treatment of congenital club foot. J Bone Joint Surg (Am) 1980; 62: 23-31.

9. Cooper DM, Dietz FR. Treatment of idiopathic clubfoot: a thirty-year followup note. J Bone Joint Surg (Am) 1995; 77-A: 1477-89.

10. Ponseti IV. Congenital clubfoot: fundamentals of treatment. Oxford, Oxford University Press, 1996.

11. Zimbler S. Nonoperative management of the equinovarus foot: long term results. In: Simons GW, eds. The clubfoot. New York: Springer-Verlag, 1994: 191-3. 
12. Dres-Goyeneche Rodolfo, D'Elia Martin, Lanfranchi Lucas, Groiso Jorge. Clubfoot nonsurgical treatment with Ponseti technique. J Bone Joint Surg (Br) 2002; 84: Suppl III.p292.

13. Pirani S, Zeznik L, Hodges D. Magnetic resonance imaging study of the congenital clubfoot treated with the Ponseti method. J PediatrOrthop2001; 21: 719-26.

14. Goksan GB. Treatment of congenital clubfoot with the Ponseti method. ActaOrthopTraumatolTurc 2002; 36(4): 281-7.

15. Pirani S. The Ponseti method and results in developing nations. Presented at the symposium on conservative methods on the treatment of clubfeet. SICOT. August 30, 2002; San Diego, CA.

16. Colburn M, Williams M. Evaluation of the treatment of idiopathic club foot by using the Ponseti method. J Foot Ankle Surg. 2003; 42(5): 259-67.

17. Morcuende JA, Dolan LA, Dietz FR, Ponseti IV. Radical reduction in the rate of extensive corrective surgery for club foot using the Ponseti method. Pediatrics. 2004; 113(2): 376-80.

18. Segev E, Keret D, Lokiec F, Yavor A, Wientroub S, Ezra E, Hayek S. Early experience with the Ponseti method for the treatment of congenital idiopathic club foot. Isr Med Assoc J. 2005; 7(5): 307-310.

19. Bor N, Herzenberg JE, Frick SL. Ponseti management of club foot in older infants. ClinOrthopRelat Res. 2006; 444: 224-28.

20. Ponseti IV, Zhivkov M, Davis N, Sinclair M, Dobbs MB, Morcuende JA. Treatment of the complex idiopathic club foot. ClinOrthopRelat Res. 2006; 451: 171-76.

21. Lavy CB, Mannion SJ, Mkandawire NC, Tindall A, Steinlechner C, Chimangeni S, Chipofya E. Clubfoot treatment in Malawi- a public health approach. DiabilRehabil 2007; 29: 11-120: 857-62.

22. Van Bosse HJ. Ponseti treatment for clubfeet: an international perspective. CurrOpinPediatr. 2011; 23(1): 41-5.

23. Kazibwe $\mathrm{H}$, Struthers $\mathrm{P}$. Barriers experienced by parents of children with clubfoot deformity attending specialized clinics in Uganda. Trop Doct2009; 39(1): 15-18.

24. Janicki JA, Narayanan UG, Harvey BJ, Roy A, Weir S, Wright JG. Comparison of surgeon and physiotherapist directed Ponseti treatment of idiopathic clubfoot. J Bone Joint Surg Am 2009; 91(5): 1101-8. 
25. Shack N, Eastwood DM. Early results of a physiotherapist delivered Ponseti service for the management of idiopathic congenital talipesequinovarus foot deformity. J Bone Joint Surg $\mathrm{Br}$ 2006;
88(8):1085-89. 